\section{Tremorless Rhythm}

SrR,-I would like to comment on the article by O. Lippold on the origin of the alpha rhythm (Nature, 226, 616; 1970). It cannot be quite true, as Dr Lippold says, that the alpha rhythm is genorated by physiological tremor in the extra-ocular muscles modulating the field set up by the standing potential of the eye. Although Dr Lippold showed evidence for a correlation, the causal relation is doubtful because an alpha rhythm also ean appear without physiological tremor of the extra-ocular muscles. I have several times observed a clear occipital alpha rhythm in curarized, non-anaesthetized cats. An example of this is shown in Fig. 1. The animal was in the dark with the contralatcral eye held open with an eyelid speculum. The recording was performed mono-

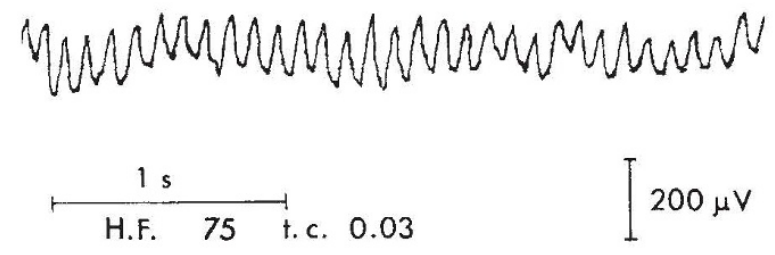

Fig. 1. Alpha rhythm in paralysed, non-anaesthetized cat rocorded directly from occipital cortex.

polarly with spring mounted chlorided silverball electrodes from the pia mater in area 17. The indifferent electrode was inserted in the ipsilateral temporal muscle. This cat, weighing $2.5 \mathrm{~kg}$, received as premedication $2.5 \mathrm{mg}$ of haloperidol, $15 \mathrm{mg}$ of pethidine, and $0.5 \mathrm{mg}$ di-Adreson Aquosum intramuscularly. All incision places were infiltrated with procaine (2 per cent). Paralysis occurred with continuous infusion with alloferine $(0.25 \mathrm{mg} / \mathrm{h})$. Artificial respiration was performed with the Amsterdam infant ventilator and was checked with blood gas values. Body temperature was held constant at $38 \cdot 5^{\circ} \mathrm{C}$.

So paralysed eats without physiological tremor of the extra-ocular muscles can still have an occipital alpha rhythm.

It scems to me that Dr Lippold should think of some other explanation. Maybe the eye tremor is influenced by the alpha rhythm.

Sincerely yours,

\section{P. VAN HASSELT}

Laboratory of General Neurophysiology,

University of Nijmegen,

Geert Grooteplein Noord 21,

Nijmegen,

The Netherlands.

\section{No Future in the Averaged Scalp}

SIR,--Dr Lippold (Nature, May 16) has briefed an excellent special plea, but his case against the cerebral origin of "alpha rhythm" is incomplete. His introductory comments betray prejudice. Who, nowadays, portrays the cortical neurones as "beating in unison" at a frequency of about $10 \mathrm{~Hz}$ ? This colourful description is reminiscent of Sherrington's late neurophilosophical poetry, but is an inaccurate summary of the contemporary encephalographer's picture.
One cannot fault Dr Lippold's excellent experiments except to suggest that, first, his publication of graphic analogies between EEG and finger tremor would be valuable in a manual of electrophysiological techniques, but they tell us nothing about the origins of the alpha: there is little sacred about 8-12 Hz, nor about its "waxing and waning"; and second, his "corneo-retinal potentials" are, to be rigorous, not that but rather EOGs, when recorded from extra-ocular derivations at the canthi. This is an important difference, since derivations from the canthi have more chance of contamination by cerebral potentials. If signal averagers are used, there is a real possibility of mistaking contamination of the oculomotor "control" record by the cerebral record for its opposite.

The integrated records are interesting, although it is not clear if the covariances were obtained by simuitaneous recording of EOG and occipital derivations. Moreover, amplitude covariance is surely thin ice for such strong conclusions. One would like to wait for some careful averaging (signal summation) data, taken over well defined, reasonably short time courses of known simultaneity. Such evidence as I have cornes from summed $204 \mathrm{~ms}$ sweeps of the binocular EOG, derived from a "bi-polar" montage with the electrodes sited at the outer canthi of either eye. These records represent the sums of 128 sweeps, sampled either at fixed intervals of one per second, or at irregularly varicd intervals of between 0.5 and $1 \cdot 0 / \mathrm{s}$. The two subjects tested were lying prone, in semi-darkness with eyes closed, and with ambient SPL of about $74 \mathrm{db}$ masking noise. They were always awake. In somo trials they were receiving single taps from a vibrator probe on the glabrous pad of the left mid-finger, and in these trials the tap initiated each averaging sweep. The contralateral postrolandic EEG, referred to right ear-lobe, was also being summed.

These "oculomotor controls", as they woro intended to be until I read Dr Lippold's paper, frequently showed a sinusoidal pattern (but not always), which varied between one and one and a half cycles per sweop. This does not suggest any evidence for an $8-13 \mathrm{~Hz}$ averaged activity, in the case of sweep frequencies fixed at $1 / \mathrm{s}$. There is no evidence of "time-locking" of this oculomotor activity to the tactile stimulation-if, indeed, it is oculomotor activity uncontaminated by scalp activity of cerebral origin.

Inspection of the pen-oscillograph record taken during these experiments indeed suggests that integration might produce the sort of correlation obtained by Dr Lippold between EOG and EEG amplitudes, if run over a sufficiently long time, and at the very low time resolution revealed in his Fig. 2. One might obtain an analogous correlation between EKG or pneumograph records and the EEG by similar methods, and this should be attempted. Of interest, howover, is the fact that my raw pen records show that large single oculomotor responses rarely correlate with anything detectable in the raw EEG, whereas smaller rhythms in the EOG often do. Which record is the "contaminator"? Admittedly, my scalp derivation was not occipital, but from $\mathrm{C}_{4}$; nevertheless, alpha (around $10 \mathrm{~Hz}$ ) bursts are regular and frequent from this derivation.

I have no encephalographical axe to grind. I am merely a student who has spent too much time on the technical problems of interpreting computer-summed evoked responses, and who now believes there is little productive future in the averaging of data from the hairy, horny scalp.

Yours faithfully,

Hutow Stowele

Psychobiology Research Center,

Department of Psychology,

The Florida State University,

Tallahassee 32306 . 